\title{
Strain- and Defect-Enhanced Cavity Formation and Au Precipitation at the Interfaces of a $\mathrm{ZrO}_{2} / \mathrm{SiO}_{2} / \mathrm{Si}$ Heterostructure
}

\author{
P. D. Edmondson,* C. M. Wang,* Z. Zhu,* F. Namavar**, W. J. Weber,* and Y Zhang* \\ * Pacific Northwest National Laboratory, PO Box 999, Richland, WA 99352 \\ ** University of Nebraska Medical Center, Omaha, NE 68198
}

Zirconia is an important ceramic material with a wide range of potential applications in the space, microelectronics and nuclear industries. In particular, it has been proposed to use zirconia as a high- $k$ gate dielectric in the fabrication of complementary-metal-oxide-semiconductor (CMOS) devices to continue the reduction of scaling of such devices in accordance with Moore's law. Recently nanostructured materials with grain sizes of $<100 \mathrm{~nm}$ have been attracting great interest due to the ability to tailor the physical, chemical, electrical and optical properties by varying the grain size. With a view to this, we have studied the effect of $2 \mathrm{MeV} \mathrm{Au}{ }^{+}$irradiation (at temperatures of 160 and $400 \mathrm{~K}$ ) on a nanocrystalline- $\mathrm{ZrO}_{2} / \mathrm{SiO}_{2} / \mathrm{Si}$ heterostructure paying particular attention to the interfacial regions. During the irradiation, defect- and strain-enhanced cavity formation and Au precipitation were observed to occur at the interfaces, in addition to the loss of oxygen and a growth in the grain size of the nanocrystalline- $\mathrm{ZrO}_{2}$ layer. The morphology of the cavities was observed to be dependent on the damage state of the underlying Si lattice, with elongated cavities forming when crystallinity is retained in the damaged $\mathrm{Si}$ substrate, and spherical cavities forming when the substrate is fully amorphised. As the ion fluence increases, the cavities appear to stabilise and begin to act as gettering sites for the Au. As the cavities become fully saturated with $\mathrm{Au}$, the $\mathrm{ZrO}_{2} / \mathrm{SiO}_{2}$ interface then acts as a gettering site for further Au precipitation. We will discuss these results in terms of the diffusion of oxygen vacancies in the $\mathrm{ZrO} 2$ film being trapped at the $\mathrm{ZrO}_{2} / \mathrm{SiO}_{2}$ interface, forming and limiting the growth of the cavities, the role of lattice strain on the morphology of the cavities, and the effect of the binding free energy of the cavities on the Au precipitation. 